\title{
'||||||||||||||||||||||||||||||||||||||||||||||||||||||||||||||.
}

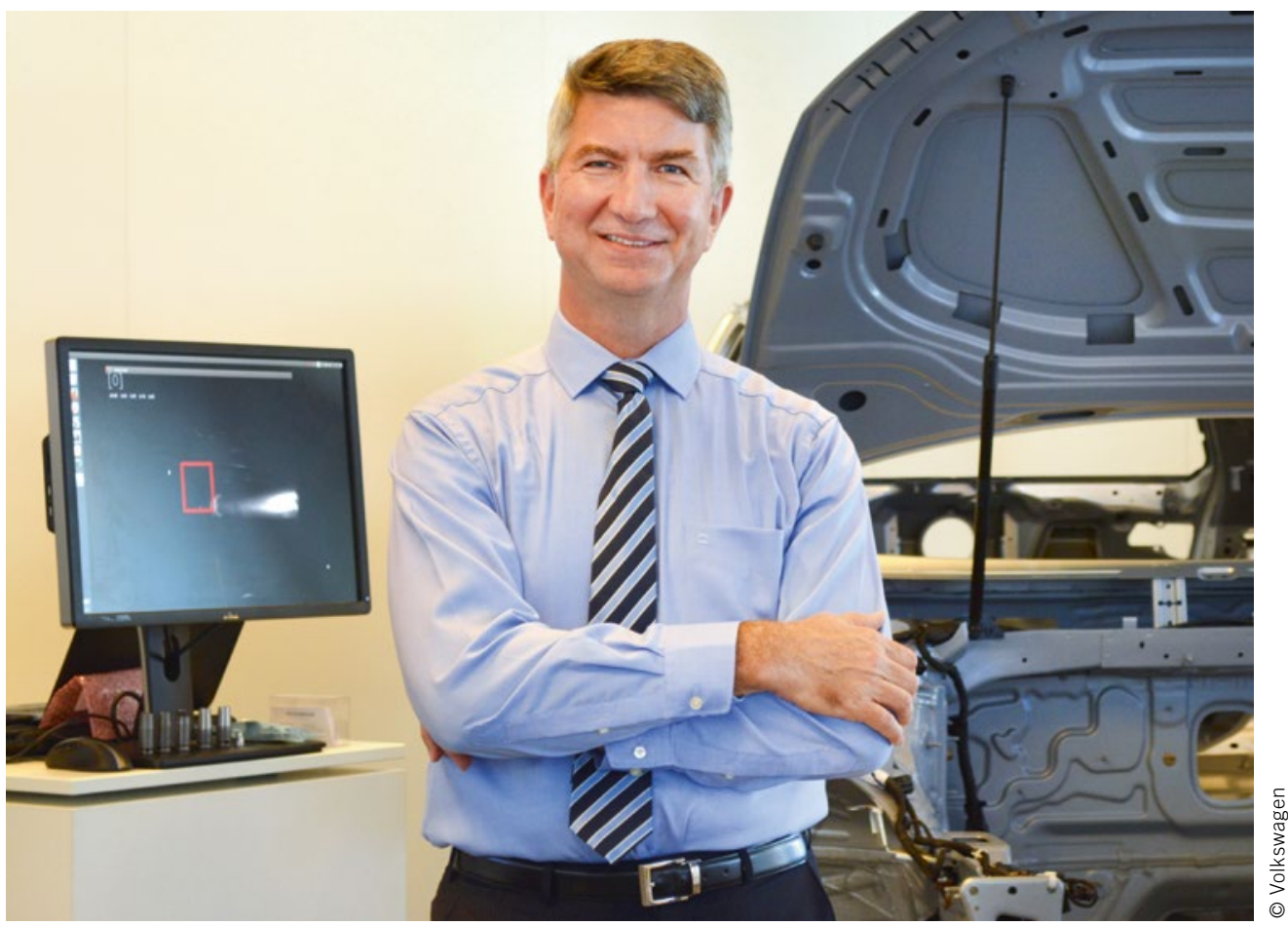

Dr.-Ing. Ulrich Eichhorn

Leiter der Konzern Forschung und Entwicklung der Volkswagen AG,

ATZ-Beirat

\section{Vernetztes Fahren - Was ist noch zu tun?}

Heute vergeht kaum keine Woche, ohne dass ein Fahrzeughersteller oder andere Unternehmen etwas zum automatisierten Fahren erklären. Autonome Fahrzeuge werden bereits zum Ende dieser Dekade in Aussicht gestellt. Die Digitalisierung des Fahrzeugs hat zwar bereits vor über 20 Jahren begonnen, digitale Ökosysteme ermöglichen jedoch erst heute neue Geschäftsmodelle. Wird diese Disruption nun zu einer erfolgreich bewältigten Chance der klassischen Automobilindustrie, oder wird es ihr wie heute praktisch verschwundene Bereiche der Old Economy ergehen? Unstrittig ist: Verkehr und Fahrzeug werden sich verändern. Gewonnene Zeit kann während der Fahrt für andere Dinge genutzt werden. Der Verkehr wird sicherer und komfortabler.

Was ist noch zu tun? Die Entwicklung der Technik schreitet ohne Zweifel mit großen Schritten voran. Inzwischen werden dem Thema Vernetzung bei vielen Unternehmen beträchtliche Ressourcen gewidmet. Methoden der künstlichen Intelligenz und des Deep-Learning versprechen bisher ungeahnte Möglichkeiten. Moderne Prozessorgenerationen zeigen Wege auf, die notwendige beträchtliche Rechenleistung ins Automobil zu bringen. Neueste Sensorgenerationen werden ein komplettes Umfeldmodell der Fahrzeugumgebung erzeugen können.

Die Sicherheit eines Fahrzeugs, also ein unfallfreies Fahren, sollte durch eigene Sensorik stets gewährleistet sein. Warum ist dann aber immer vom automatisierten und vernetzten Fahren die Rede? Ein komfortables - vorausschauendes - Dahingleiten wird ohne Vorwissen über die vor dem Fahrzeug liegende Verkehrssituation in Form einer hochpräzisen, hochaktuellen Karte kaum zu erreichen sein. Eine solche Karte kann über eine Flotte von vernetzten Fahrzeugen erzeugt, aktuell gehalten und über mobile Onlinedienste verteilt werden. Heute kooperieren wir Menschen auf vielfältige subtile Art und Weise mehr oder weniger zugunsten eines effizienten Verkehrsflusses. Hier sind neue Verfahren gefragt, wie wir zukünftig diese Kooperation zwischen manuell und automatisch fahrenden Fahrzeugen effizient sicherstellen.

Automatisiertes Fahren nutzt der Gesellschaft ohne Frage bei Umweltschutz, demografischem Wandel, Wirtschaft und Verkehrssicherheit. Potenzielle Gefahrensituationen bewältigt das technische System in der Regel innerhalb seiner Funktionsund Gebrauchsgrenzen schneller, rationaler, vorausschauender und daher besser als viele menschliche Fahrer. Allerdings, das perfekte unfallfreie technische System ist Vision. Gefahrenstellen gerade mit ungeschützten Verkehrsteilnehmern sind in urbanen Umgebungen zu erwarten. Leitsätze und Verhaltensregeln für alle möglichen Gefahrensituationen sollten dazu in einem breiten gesellschaftlichen Diskurs erarbeitet werden. Hierfür hat die Bundesregierung bereits eine Ethikkommission eingesetzt. 